Editorial

\title{
Nanotecnología y biomedicina
}

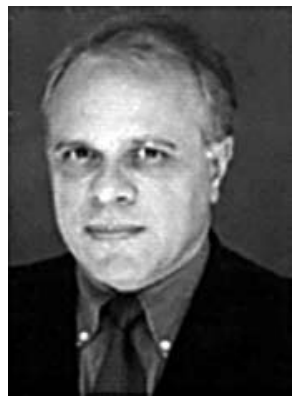

$\mathrm{L}$ a nanotecnología es el desarrollo de dispositivos fabricados a escalas atómicas, moleculares y macromoleculares, en rango nanométrico. Estas nanopartículas tienen importantes aplicaciones en el campo médico, especialmente en las áreas de diagnóstico y terapia. Ya vemos avances en el desarrollo de dispositivos con tecnología nano para la detección temprana de enfermedades infecciosas e incluso de cáncer. Estos avances también presentan enormes beneficios en los campos terapéuticos para el desarrollo de medicamentos con metodologías que permiten efectos específicos en el lugar deseado.

El impulso de mayor importancia para la ciencia e ingeniería a escala nanométrica se dio con el anuncio en los Estados Unidos de la Iniciativa Nacional para la Nanotecnología (NNI por sus siglas en inglés), en enero de 2000. La investigación reciente en bio-sistemas a escala nano ha dado paso a la confluencia dinámica de las ciencias físicas, la ingeniería molecular, la biología, la biotecnología y la medicina. Esto nos ha brindado la oportunidad para comprender mejor los sistemas vivos y los sistemas inteligentes, los procesos biotecnológicos, la síntesis de nuevos medicamentos y su dosificación y entrega específica, la regeneración de tejidos, la ingeniería neuro-mórfica y el desarrollo de un medio ambiente sostenible.

En años recientes, la nanotecnología se ha desarrollado al punto que es posible producir, caracterizar y diseñar específicamente las propiedades funcionales de las nanopartículas para aplicaciones clínicas. Se destacan las nanopartículas magnéticas, que han permitido mejorar las imágenes de las resonancias magnéticas (MRI), el tratamiento hipertérmico de células malignas y la manipulación de membranas celulares, entre otras. También está la producción de fibras ultra finas solidas y continuas que van desde unos pocos nanómetros hasta cientos de nanómetros con superficies y estructuras moleculares internas controladas.

En el campo de los polímeros, es posible el desarrollo de superficies de nanofibras con integridad estructural que pueden ser diseñadas para demostrar características bioquímicas específicas. Lo que podría llevar a que estos tejidos, de nanofibras con química de superficie específica, se puedan adherir a células para controlar las funciones de éstas. Las características de estos tejidos (mallas) de nanofibras demuestran una morfología y química similar a la matriz extracelular del tejido natural (amplio rango de distribución de diámetro de poros, alta porosidad, propiedades mecánicas efectivas y propiedades bioquímicas específicas), presentando la posibilidad de aprovechar polímeros y bio-polímeros en aplicaciones como membranas multifuncionales, elementos estructurales biomédicos (el andamiaje utilizado en la ingeniería de tejidos, recubrimientos para heridas, órganos artificiales, reparación vascular, etc.), textiles especializados y filtros para partículas sub-micra, entre muchas más aplicaciones de nanofibras poliméricas en el campo de la biomedicina. 
Estos avances requieren de investigación interdisciplinaria para potenciar el desarrollo de los nanomateriales en biología y medicina. Es fundamental que muchas disciplinas como la física, la química, la microbiología, la biología celular, las ciencias de los materiales, las ingenierías, la informática, etc., contribuyan al diseño, síntesis y fabricación de dispositivos funcionales y biocompatibles a escala nano. Mediante la mímica en tamaño nano de entidades funcionales como el ADN y las proteínas, podremos abrir oportunidades prometedoras para el desarrollo de bio-sensores, biochips y bio-plataformas. Estas son ventanas de beneficios y retos que se abren ante la inminente manufactura masiva de nanopartículas y nano-redes bio-compatibles que se pueden enlazar con objetos biológicos.

Entre los retos que debemos enfrentar están los relacionados con los costos, la innovación y la calidad de los nano-dispositivos que se fabriquen para que tengan un impacto real dentro del campo emergente de la bio-nanotecnología. La convergencia de la nanotecnología y la biomedicina, con apoyo multidisciplinario, traerá beneficios en el descubrimiento de nuevas moléculas y la manipulación de las existentes, que podrán acelerar el paso desde la investigación básica hacia el desarrollo de prototipos y productos prácticos y así mejorar muchos servicios de la salud.

Imaginemos un mundo futuro donde nano-dispositivos médicos sean implantados rutinariamente o inyectados al torrente sanguíneo para monitorear la salud y participar automáticamente en la reparación de sistemas alternos al patrón normal. Los avances en este campo de la ciencia se darán mediante la colaboración de grupos de investigación en áreas complementarias, así como mediante continua colaboración internacional, compromiso y voluntad política de los Estados para hacerlos una realidad. Desarrollar e implementar exitosamente la colaboración internacional aumenta la perspectiva global de la investigación y reúne los beneficios para el bien de la humanidad. Quedan muchos obstáculos en el camino de la nanotecnología aplicada a la medicina; estos los tendremos que allanar, teniendo en cuenta también los peligros y las consecuencias negativas si estos nuevos conocimientos y desarrollos caen en manos equivocadas.

El potencial de la nanotecnología es amplio y mucho de su espectro está aún por descubrirse. Ya conocemos sus bondades y aplicaciones y, más allá de las consideraciones éticas y legales, también debemos considerar los posibles riesgos que implica el uso de estas nanopartículas. Nuestros Estados y el mundo entero se deben preparar y fijar políticas claras en cuanto al uso y alcance de la nanotecnología en campos como la biología y la medicina moderna. En muchos países la investigación en nanotecnología es prioritaria y esperamos ansiosamente a que su relevancia en el campo de la biomedicina aumente en el futuro cercano. NO

Albert Ortiz M. Psiquiatra, City College of the City University of New York Asesor de Proyectos Internacionales Centro de Excelencia en Nuevos Materiales - CENM www.cenm.org-albertor@univalle.edu.co 